\title{
Show da Física: uma aprendizagem significativa
}

Resumo: $O$ presente trabalho visa relatar a experiência do projeto Show da Física, realizado por um professor atuante em uma escola rural da rede estadual paulista. Para o aporte teórico os autores elucidados são Gauthier, Bissonnette e Richard (2014), Bissonnette e Richard (2013), Roldão (2009), Izquierdo (2011) entre outros. Como procedimento metodológico adotamos a descrição do contexto escolar, descrição do projeto Show da Física, da distribuição dos experimentos, da montagem e organização da sala de aula, da apresentação no dia da feira e as consequências do pós-projeto. Ela se encerrou com uma avaliação que busca um feedback do aluno e da sua experiência frente a todo o processo. Conclui-se que a estratégia de ensino descrita promoveu elementos que são relevantes ao desenvolvimento global do aluno, como: Oralidade, trabalho em equipe, organização, pesquisa, apresentação das ideias e respeito aos prazos de cada etapa. Observa-se, ainda, que o papel do professor foi fundamental para um ensino eficaz.

Palavras-Chave: Estratégia de ensino. Física. Projeto.

\author{
Danilo Garufe Gomes ${ }^{1}$ \\ Ana Maria Gimenes Corrêa Calil ${ }^{2}$ \\ Antonio Rodolfo Souza da Silva ${ }^{3}$ \\ Juliana Marcondes Bussolotti ${ }^{4}$ \\ Laura Rechdan Ribeiro Novaes ${ }^{5}$ \\ Virginia Mara Próspero da Cunha ${ }^{6}$
}

\footnotetext{
${ }^{1}$ Mestre em Educação pela Universidade de Taubaté (UNITAU). Professor de Educação Básica da rede estadual paulista. E-mail: danilogarufe@gmail.com ORCID iD: http://orcid.org/0000-0003-3428-5908

${ }^{2}$ Doutora em Educação (Psicologia da Educação) pela Pontifícia Universidade Católica (PUC-SP). Professora e coordenadora do Mestrado Profissional em Educação na Universidade de Taubaté (UNITAU). E-mail: ana.calil@unitau.br ORCID iD: http://orcid.org/0000-0002-4578-0894

${ }^{3}$ Mestre em Educação pela Universidade de Taubaté (UNITAU). Professor de Educação Básica da rede estadual paulista. E-mail: danilogarufe@gmail.com ORCID iD: http://orcid.org/0000-0003-2846-4379

${ }^{4}$ Doutora em Geografia pela Universidade Estadual Paulista. Professora coordenadora adjunta do Mestrado Profissional em Educação da Universidade de Taubaté (UNITAU). E-mail: julianabussolotti@ gmail.com ORCID iD: http://orcid.org/0000-0002-8560-0974

${ }^{5}$ Mestre em Educação pela Universidade de Taubaté (UNITAU). Diretora da escola da rede municipal de Taubaté. E-mail: 1rechdan@hotmail.com ORCID iD: http://orcid.org/0000-0002-5432-791X

${ }^{6}$ Doutora em Educação (Psicologia da Educação). Professora permanente do Mestrado Profissional Em Educação da Universidade de Taubaté (UNITAU). E-mail: vimaracunha@terra.com.br. ORCID iD: http://orcid.org/00000002-1919-5480
} 


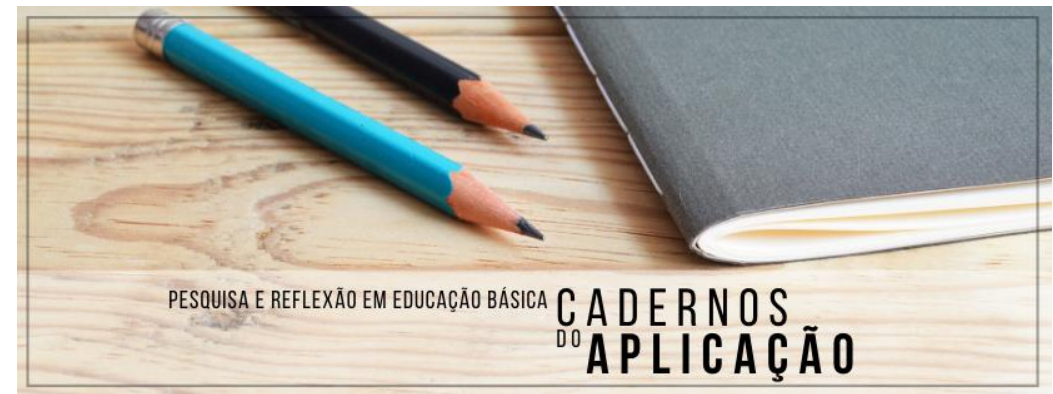

Cadernos do Aplicação

https://seer.ufrgs.br/CadernosdoAplicacao

Publicação Ahead of Print

ISSN 2595-4377 (online)

Porto Alegre | jul-dez. 2021 | v.34 | n.2

\title{
Physics show: a meaningful learning
}

\begin{abstract}
The present work aims to report the experience of the Show da Fisica project, carried out by a teacher working in a rural school in the state of São Paulo. For the theoretical contribution the authors elucidated are Gauthier, Bissonnette and Richard (2014), Bissonnette and Richard (2013), Roldão (2009), Izquierdo (2011) among others. As a methodological procedure we adopted the description of the school context, description of the Show da Fisica project, the distribution of experiments, the assembly and organization of the classroom, the presentation on the day of the fair and the consequences of the post-project. It ended with an evaluation that seeks feedback from the student and his experience regarding the whole process. It is concluded that the teaching strategy described promoted elements that are relevant to the student's global development, such as: Orality, teamwork, organization, research, presentation of ideas and respect for the deadlines of each stage. It is also observed that the role of the teacher was fundamental for effective teaching.
\end{abstract}

Keywords: Teaching strategy. Physics. Project.

\section{Espectáculo de física: un aprendizaje significativo}

Resumen: El presente trabajo tiene como objetivo relatar la experiencia del proyecto Show da Física, realizado por un docente que trabaja en una escuela rural en el estado de São Paulo. Para el aporte teórico los autores elucidaron son Gauthier, Bissonnette y Richard (2014), Bissonnette y Richard (2013), Roldão (2009), Izquierdo (2011) entre otros. Como procedimiento metodológico se adoptó la descripción del contexto escolar, descripción del proyecto Show da Física, la distribución de experimentos, el montaje y organización del aula, la presentación el día de la feria y las consecuencias del post-proyecto. Finalizó con una evaluación que busca la retroalimentación del alumno y su experiencia sobre todo el proceso. Se concluye que la estrategia docente descrita promovió elementos relevantes para el desarrollo global del alumno, tales como: Oralidad, trabajo en equipo, organización, investigación, presentación de ideas y respeto a los plazos de cada etapa. También se observa que el rol del docente fue fundamental para una enseñanza eficaz.

Palabras clave: Estrategia de enseñanza. Física. Proyecto.

\section{Introdução}

A disciplina de Física, na rede estadual de São Paulo, é distribuída nas três séries do ensino médio, com duas aulas semanais em cada série. São Paulo (2009) traz a ementa deste componente curricular, onde Mecânica Clássica e Astronomia são contempladas na primeira 


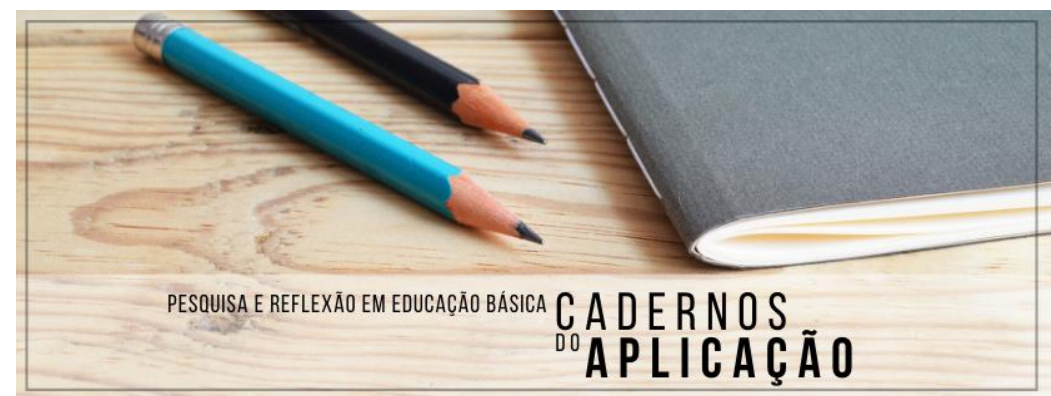

Cadernos do Aplicação

https://seer.ufrgs.br/CadernosdoAplicacao

Publicação Ahead of Print

ISSN 2595-4377 (online)

Porto Alegre | jul-dez. 2021 | v.34 | n.2

série, Termodinâmica e Ondulatória na segunda série e, por fim, Eletromagnetismo e Física Moderna na terceira série.

A estratégia de ensino "Show da Física" apresentou-se como um projeto, nos moldes de uma feira de ciências, a fim de ampliar as possibilidades de aprendizagem dos alunos do ensino médio, ao desenvolverem os experimentos, analisá-los e apresentá-los. Quanto aos alunos do ensino fundamental, o projeto oportunizou um primeiro contato dos educandos com a Física, durante a visitação no dia que ocorre a feira.

\section{Objetivos}

Tem-se, como objetivo geral, analisar sistematicamente a atividade pedagógica de ensino. Os objetivos específicos são: descrever detalhadamente a prática do "Show da Física" e avaliar esta atividade, a partir da fundamentação teórica.

\section{Método}

A escola onde o projeto foi realizado pertence à rede pública paulista, contempla o modelo de ensino regular, está situada na zona rural de uma cidade do Vale do Paraíba e atende alunos dos anos finais do ensino fundamental e do ensino médio.

A instituição foi avaliada no Índice de Desenvolvimento da Educação do Estado de São Paulo (IDESP) em 2018 com nota 5,00 e 3,99 nos respectivos ciclos. Neste mesmo ano, a escola atendeu um total de 170 alunos, sete classes - sendo uma classe de cada ano/série, e funcionava nos turnos matutino e vespertino. A escola implantou o ensino médio no ano de 2015 a partir de uma demanda da comunidade escolar. 
Quadro 1 - Organização do Projeto

\begin{tabular}{|c|c|c|}
\hline \multicolumn{3}{|c|}{ SHOW DA FÍSICA } \\
\hline $\begin{array}{c}\text { Anos Finais } \\
\text { Ensino Fundamental }\left(6^{\circ} \text { ao } 9^{\circ} \text { ano }\right)\end{array}$ & $\begin{array}{c}1^{\mathrm{a} e} 2^{\mathrm{a}} \text { série } \\
\text { Ensino Médio }\end{array}$ & $\begin{array}{c}3^{\mathrm{a}} \text { Série } \\
\text { Ensino Médio }\end{array}$ \\
\hline $\begin{array}{c}\text { Visitação em grupos de } 15 \text { alunos } \\
\text { por vez. }\end{array}$ & $\begin{array}{c}\text { Construção e apresentação } \\
\text { dos experimentos. }\end{array}$ & $\begin{array}{c}\text { Montagem da sala e } \\
\text { apoio durante o projeto. }\end{array}$ \\
\hline
\end{tabular}

Fonte: Elaborado pelos autores, 2020.

No ano de 2018, foi realizada a $3^{\mathrm{a}}$ edição deste projeto na escola, e é sobre essa edição que este trabalho se refere. Esta atividade pedagógica foi baseada no projeto homônimo, que acontece de maneira itinerante, elaborado pela Universidade de Taubaté (UNITAU), no qual quem apresenta os experimentos às escolas de educação básica são os graduandos dos cursos de Licenciatura em Matemática e Licenciatura em Física. Este projeto também é apresentado aos visitantes da Feira das Profissões promovida pela própria universidade.

A preparação do projeto consistiu na distribuição dos experimentos em grupos compostos por três a quatro alunos da $1^{\mathrm{a}}$ e $2^{\mathrm{a}}$ séries do ensino médio. Os experimentos contemplaram habilidades e competências da grade curricular das respectivas séries das disciplinas de Física e Química.

O professor promoveu um encontro de aproximadamente duas horas com cada uma das séries citadas anteriormente. Nesta aula foram apresentados, com o auxílio de um datashow, vídeos de experimentos retirados do canal Manual do Mundo ${ }^{7}$ - hospedados na plataforma YouTube - sempre acompanhados da explicação do professor. Todos os alunos assistiram, comentaram e aprenderam como construir e a elaborar uma justificativa do funcionamento de cada um dos experimentos.

A feira foi uma atividade pedagógica interdisciplinar de ensino que envolveu os componentes curriculares de Física e Química do ensino médio. O projeto, que acontece anualmente no mês de novembro, consiste em uma feira de ciências com uma atmosfera $\mathrm{Hi}$ -

\footnotetext{
${ }^{7}$ Sítio: https://www.youtube.com/user/iberethenorio
} 
$T e c h^{8}$ e é composta por experimentos desenvolvidos e apresentados pelos próprios alunos do ensino médio aos alunos dos anos finais do ensino fundamental.

Alguns dos experimentos realizados na 3 $3^{\mathrm{a}}$ edição do Show da Física em 2018 foram: Nó em pingo d'água (tensão superficial dos líquidos); Lata adestrada (princípio da conservação de movimento e energia potencial elástica); Como enxergar sua própria voz (ondulatória do som); Degelo colorido (densidade dos líquidos, água e óleo); Leite psicodélico (polaridade, solubilidade e como detergentes reagem à gordura); Cadeira giratória (princípio da conservação de energia e aceleração centrípeta); Pilha de limão (demonstração da corrente elétrica e da tensão elétrica por meio de transformação química).

Após a exibição dos vídeos e a explicação de cada experimento, os alunos foram divididos em grupos e foi solicitado que houvesse um consenso sobre qual experimento cada grupo iria apresentar no dia da realização do projeto. Os grupos chegaram a um acordo e não houve necessidade de sorteio.

Ao final deste encontro de duas horas, o professor convidou cada grupo a trazer um segundo experimento para apresentar no dia da feira. Este poderia ser da preferência dos estudantes, com a possibilidade de pesquisar na Internet, livros ou ainda em canais do YouTube que trouxessem novas ideias. Este segundo experimento deveria abranger ainda os componentes de Física e/ou Química, porém não era necessário que a experiência contemplasse alguma habilidade específica referente à série que o aluno cursava.

Um segundo encontro de duas horas foi promovido vinte dias após o primeiro. Neste encontro os alunos deveriam ter os experimentos desenvolvidos e saber explicar a justificativa dos fenômenos envolvidos naquela experiência. O professor se reuniu com cada um dos grupos individualmente para constatar o funcionamento dos ensaios, ouvir a explicação dos alunos e sanar alguma dúvida que ainda pudessem apresentar.

A dez dias da realização do projeto Show da Física, o professor reuniu os alunos da $3^{\text {a }}$ série do ensino médio e realizou um esboço em forma de croqui com o objetivo de visualizar como ficaria à disposição da sala montada com todos os experimentos e dispositivos eletrônicos instalados. Neste mesmo encontro, o professor convidou os alunos a trazerem itens que pudessem decorar ou caracterizar o efeito $\mathrm{Hi}$-Tech buscado nesta feira de ciências.

\footnotetext{
${ }^{8}$ Hi-Tech: High Tecnology (Alta Tecnologia).
} 


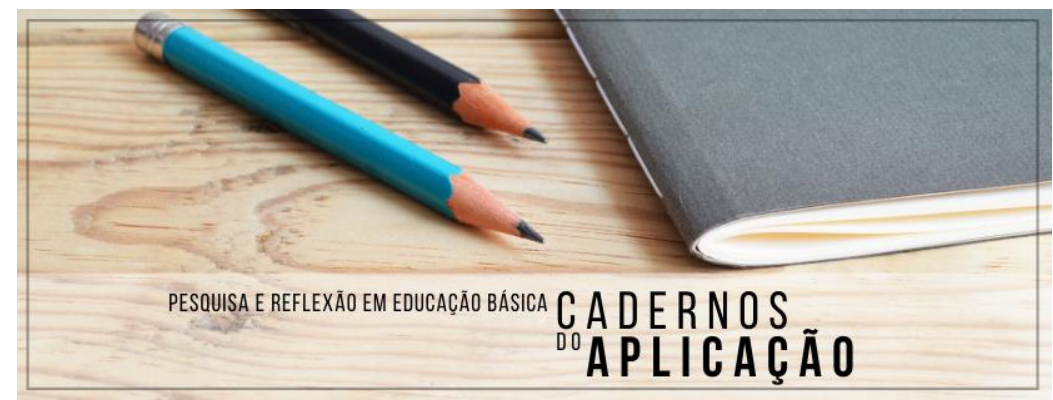

Cadernos do Aplicação

https://seer.ufrgs.br/CadernosdoAplicacao

Publicação Ahead of Print

ISSN 2595-4377 (online)

Porto Alegre | jul-dez. 2021 | v.34 | n.2

A montagem da sala de aula onde ocorreram as apresentações foi realizada pelos alunos em um espaço dedicado apenas ao evento, um dia antes da feira. Foi necessário que os alunos - que estudam no período da manhã - concluíssem a montagem e instalação de todos os componentes do ambiente da feira no contraturno, sendo, portanto, um trabalho de aproximadamente oito horas no dia que precedeu a feira.

No dia da apresentação do Show da Física, os alunos da $1^{\mathrm{a}}$ série e $2^{\mathrm{a}}$ série permaneceram em cada bancada com o seu respectivo experimento. Os alunos da $3^{\mathrm{a}}$ série constituíam a equipe de apoio para guiar os alunos do $6^{\circ}$ ao $9^{\circ}$ ano durante a visitação à sala do Show da Física. Por uma questão de espaço físico, vale ressaltar que não foram todos os componentes do grupo que participaram da apresentação oral aos visitantes, sendo apenas dois integrantes de cada grupo que realizaram esta tarefa.

Os alunos do ensino fundamental entraram em grupos de 15 para a visitação e foram orientados pelos alunos da $3^{\text {a }}$ série a visitarem todas as bancadas e fazerem perguntas caso tivessem alguma dúvida sobre algum experimento. A passagem de cada grupo de 15 crianças durou cerca de 20 minutos, até que todos pudessem usufruir de todas as experiências apresentadas.

Após a realização do Show da Física, foi feito um debate coletivo com cada série do ensino médio para levantar os pontos positivos e negativos do projeto, em quais aspectos ele poderia ser aprimorado e as dificuldades encontradas na realização ou apresentação do experimento. Cada aluno respondeu um questionário, conforme a Figura 1, e entregou para a apreciação do professor responsável pelo projeto. 
Figura 1 - Questionário de Avaliação do Projeto

QUESTIONÁRIO DE AVALIAÇÃO DO PROJETO "SHOW DA FÍSICA"

Nome: $\mathrm{n}^{\circ}$ Série:

1) O que você mais gostou do projeto "Show da Física"?

2) Qual foi a sua maior dificuldade?

3) O que você achou do experimento que desenvolveu e apresentou?

4) Quais sugestões você daria para o projeto melhorar?

5) Em uma nota de 0 a 10, quanto você acha que o projeto "Show da Física" contribuiu para o seu aprendizado?

\begin{tabular}{|l|l|l|l|l|l|l|l|l|l|l|}
\hline $\mathbf{0}$ & $\mathbf{1}$ & $\mathbf{2}$ & $\mathbf{3}$ & $\mathbf{4}$ & $\mathbf{5}$ & $\mathbf{6}$ & $\mathbf{7}$ & $\mathbf{8}$ & $\mathbf{9}$ & $\mathbf{1 0}$ \\
\hline
\end{tabular}

Fonte: Elaborado pelos autores, 2020.

O feedback dos alunos, de uma forma geral, foi positivo, pois avaliaram entre 8 e 10 a contribuição do projeto para sua aprendizagem. A oralidade foi a maior dificuldade apontada no decorrer do projeto, entretanto as respostas indicam satisfação com o desenvolvimento e exposição dos experimentos, sugerindo que a execução da feira foi significativa no processo formativo dos discentes.

\section{Discussão}

Segundo Gauthier, Bissonnette e Richard (2014), uma boa gestão dos aprendizados passa, necessariamente, pelo planejamento. Portanto, o docente precisa definir os objetivos de aprendizado, o que lhe permite manter o foco e selecionar as melhores atividades para aquele fim. O professor também deve verificar o alinhamento curricular, sendo necessário que o currículo esteja organizado de modo a facilitar a aprendizagem dos alunos, integrando estrategicamente os diferentes tipos de conhecimento.

A organização do projeto Show da Física apresenta-se como ação estratégica, com o objetivo de construir uma aprendizagem mais significativa no componente de Física, a fim de despertar uma tomada de consciência dos discentes. Neste sentido, "quando o aluno for questionado sobre o que aprendeu na escola, será extremamente difícil para ele nomear 


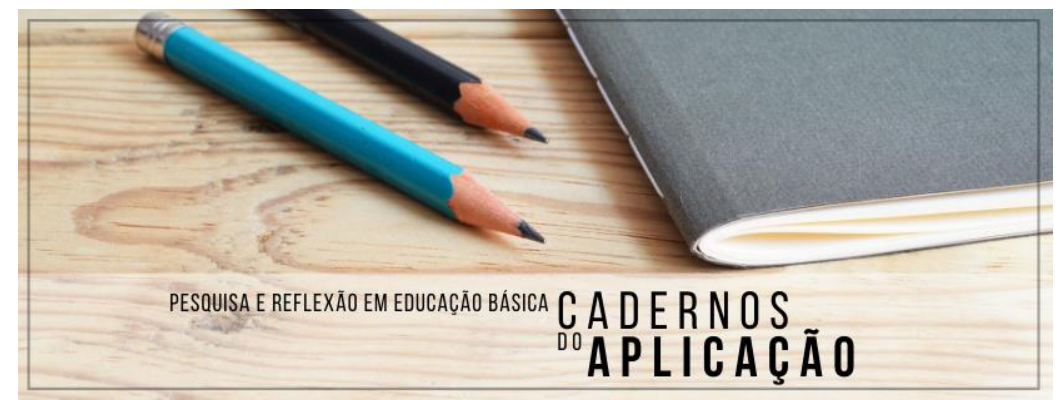

Cadernos do Aplicação https://seer.ufrgs.br/CadernosdoAplicacao

Publicação Ahead of Print

ISSN 2595-4377 (online)

Porto Alegre | jul-dez. 2021 | v.34 | n.2

explicitamente o fruto das suas aprendizagens, se ele não tomou consciência delas" (BISSONNETTE; RICHARD, 2013, p. 410).

Neste contexto, há algum tempo se destacam as metodologias ativas de aprendizagem, segundo as quais os alunos são protagonistas de seus aprendizados e aprendem de forma reflexiva. Pelas experimentações e pelos questionamentos, a compreensão torna-se mais ampla e efetiva. Assim, "as metodologias ativas estão alicerçadas em um princípio teórico significativo: a autonomia, algo explícito na invocação de Paulo Freire" (MITRE, 2008, p. 2135, grifo do autor).

Principiaremos a discussão do projeto com a fase de distribuição dos experimentos, na qual, inicialmente, o professor se reuniu com cada sala envolvida e explicou detalhadamente o que se esperava deste projeto e como seria o caminho para alcançar este objetivo, passo a passo. Apresentar explicitamente onde se espera que o aluno chegue, se justifica, pois

um objetivo deve definir o que o aluno deve ter aprendido no fim da aula. Não somente o professor deve indicar o que ele quer que o aluno aprenda, a fim de manter o foco no objetivo. [...] O objetivo imprime, portanto, uma direção clara às atividades de aprendizado que se realizam em sala de aula. Ele dá sentido às atividades organizadas durante a sala da prática guiada e [...] facilita a avaliação dos aprendizados [...] a fim de garantir um bom alinhamento curricular (GAUTHIER; BISSONNETTE; RICHARD, 2014, p. 121).

O momento em que o docente delineou cada experimento aos estudantes - com o auxílio do canal Manual do Mundo - foi crucial, pois "se apresentarmos procedimentos aos alunos e se os guiarmos em sua aplicação, eles podem desenvolver sua consciência metacognitiva" (BISSONNETTE; RICHARD, 2013, p. 419). Ainda, segundo os autores, é essa consciência que leva o aluno a refletir sobre o que e como está desenvolvendo alguma atividade, além de ter um papel fundamental nas três etapas do ensino explícito que levam a aquisição do conhecimento. Trata-se da

capacidade particular dos peritos em controlar eficientemente seus processos de realização das tarefas. [...] Esta representa a habilidade de refletir sobre o próprio pensamento, de conscientizar, controlar e supervisionar os diferentes processos mentais utilizados no tratamento da informação, a fim de otimizar o seu funcionamento (BISSONNETTE; RICHARD, 2013, p. 418). 
Ainda sobre a aula na qual, em um primeiro momento, o professor estimula a curiosidade dos alunos e, em seguida, realiza as explanações sobre cada um dos experimentos, o docente contou com auxílio de recursos multimídia como datashow e caixa de som para obter a atenção dos alunos. Este contexto contempla a primeira etapa do ensino explícito denominado por Bissonnette e Richard (2013), como 'modelagem', pois, naquele momento, além do professor estar ativando "os meios necessários à obtenção de um grau elevado de atenção por parte dos alunos", ele também "se preocupa em tornar visíveis por meio da linguagem, todas as relações a fazer entre os conhecimentos novos e anteriores" (BISSONNETTE; RICHARD, 2013, p. 407).

A prática realizada no segundo encontro, vinte dias após a primeira explicação do professor, a partir do ponto de vista de Bissonnette e Richard (2013), contempla a etapa do processo de ensino explícito, denominada 'prática guiada'. Segundo os autores, a ação do professor em dividir os discentes em grupos favorece esta etapa, já que é nesta configuração que os alunos podem validar sua compreensão trocando ideias entre si.

A 'Prática Guiada' proposta pelo professor no momento dos testes dos experimentos permite "aos alunos validar, adaptar, consolidar e aprofundar sua compreensão da aprendizagem em curso, a fim de fazer a ligação desses novos conhecimentos com aqueles que já possuem na memória de longo prazo" (BISSONNETTE; RICHARD, 2013, p. 407).

A etapa que encerra o projeto é a apresentação e demonstração aos alunos visitantes. Neste momento, o ato de explicar a montagem e os fenômenos físicos que envolvem determinado experimento científico a terceiros, implicou em um alto grau de transferência das aprendizagens. Bissonnette e Richard (2013), afirmam que a transferência está ligada ao fato de passar determinada aprendizagem de um contexto para o outro. Nesse sentido, o professor deve garantir que as tarefas tenham certo grau de similitude (tarefas alvos e tarefas fontes), assegurar que os discentes percebam essa semelhança, além de contemplar diferentes contextos.

Ao destacar esta fase do projeto, viemos ao encontro do que Gauthier, Bissonnette e Richard (2014) sugerem sobre a atuação do professor. Os autores indicam que o docente ajuste o nível de orientação das aprendizagens dos alunos de acordo com o seu nível de competência, a complexidade da tarefa proposta e o tempo disponível, sendo que os alunos partem do aprendizado guiado para um aprendizado cada vez mais autônomo. 


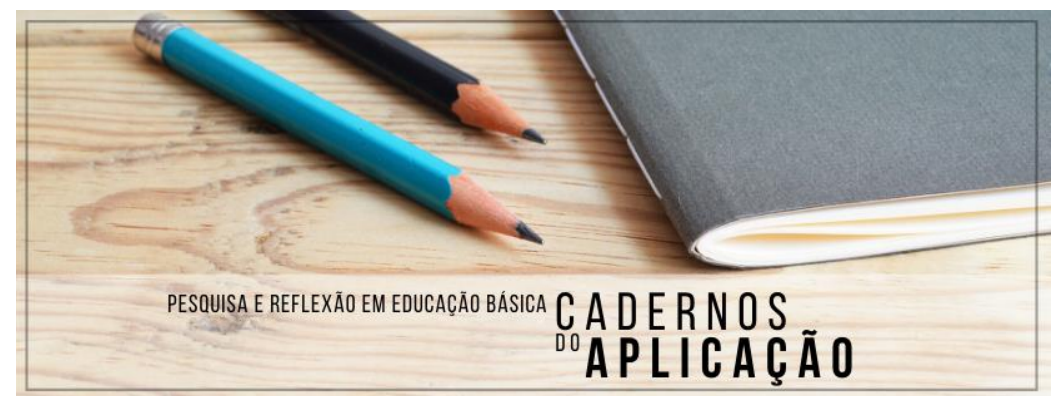

Cadernos do Aplicação

https://seer.ufrgs.br/CadernosdoAplicacao

Publicação Ahead of Print

ISSN 2595-4377 (online)

Porto Alegre | jul-dez. 2021 | v.34 | n.2

No momento da apresentação oral aos visitantes do Show da Física, a situação de ensino passa, então, consequentemente, para a prática autônoma, pois é o momento em que o aluno "reinveste sozinho, com a ajuda do seu plano de questionamento, o que ele compreendeu da modelagem e aplicou em equipe, durante a prática guiada, em alguns problemas ou questões" (BISSONNETTE; RICHARD, 2013, p. 407).

Segundo Bissonnette e Richard (2013), a prática autônoma permite melhorar a organização desses conhecimentos na memória de longo prazo. Por tratar-se da apresentação de experimentos científicos, aqui o aluno evoca principalmente sua memória semântica de conhecimentos processuais-condicionais, que está ligada a ações, sequências de ações e maneiras de fazer.

A última etapa do projeto, denominada aqui pós-projeto, trata-se do feedback fornecido pelos alunos. Ele é realizado em dois momentos: quando os discentes respondem um questionário referente à sua apresentação e quando eles participam da discussão em grupo sobre o que eles aprenderam. Esses recursos fazem parte de uma estratégia de ensino que contempla “dispositivos e modos de avaliação" (ROLDÃO, 2009, p. 64), sendo, portanto, uma avaliação escrita e uma avaliação oral. Ainda segundo Roldão (2009), a avaliação de uma situação de ensino permite que o professor reanalise a prática a fim de reorientá-la no futuro, caso necessário.

Considerando todo o projeto, podemos estabelecer uma associação das três etapas do ensino explícito proposto por Gauthier, Bissonnette e Richard (2014, p.193) com as fases do projeto do "Show da Física", como podemos observar a seguir: 


\section{Quadro 2 - Associação Ensino Explícito e Show da Física}

\begin{tabular}{|c|c|}
\hline Ensino Explícito & Projeto "Show da Física" \\
\hline $\begin{array}{c}\text { ETAPA 1 - MODELAGEM } \\
\text { Durante suas apresentações e demonstrações, o(a) } \\
\text { professor(a) se esforça para explicitar todo raciocínio } \\
\text { que estiver implícito, ensinando o quê, por que, como, } \\
\text { quando e onde fazer. }\end{array}$ & $\begin{array}{l}\text { Explicação do projeto para os alunos, } \\
\text { com orientações sobre a sua função. }\end{array}$ \\
\hline $\begin{array}{l}\text { ETAPA } 2 \text { - PRÁTICA DIRIGIDA (feedback) } \\
\text { O(a) professor(a) tira um tempo para checar o que os } \\
\text { alunos entenderam de sua apresentação ou } \\
\text { demonstração, passando-lhes tarefas, em grupo, } \\
\text { semelhantes às efetuadas durante a modelagem. }\end{array}$ & $\begin{array}{l}\text { Os alunos apresentam os experimentos } \\
\text { para o professor, com as justificativas e } \\
\text { explicitando de que forma acontece o } \\
\text { fenômeno físico relacionado ao } \\
\text { experimento científico. }\end{array}$ \\
\hline $\begin{array}{l}\text { ETAPA } 3 \text { - PRÁTICA AUTÔNOMA } \\
\text { O aluno estuda sozinho o que ele compreendeu da } \\
\text { modelagem e o que foi aplicado em grupo, durante a } \\
\text { prática dirigida, com alguns problemas ou perguntas. }\end{array}$ & $\begin{array}{l}\text { Acontece a apresentação dos } \\
\text { experimentos para os demais alunos da } \\
\text { escola. }\end{array}$ \\
\hline
\end{tabular}

Fonte: Elaborado pelos autores, 2020.

Notamos assim, que o ensino explícito se trata de uma estratégia de ensino estruturada em etapas integradas e sequenciadas, considerando que o papel do professor é essencial no ensino e no aprendizado dos alunos. Gauthier, Bissonnette e Richard (2014) ressaltam as duas grandes funções do ensino: a gestão dos aprendizados (o instruir) e a gestão da classe (o educar) as quais estão interligadas, a partir das atribuições supracitadas.

\section{Conclusão}

Com base na análise realizada, principalmente a partir das etapas do Ensino Explícito (Modelagem, Prática Guiada e Prática Autônoma), bem como os três momentos que compõem o Modelo PIC (Vide Figura 1), ambos propostos por Gauthier, Bissonnette e Richard (2014), pode-se considerar que a prática de ensino apresentada no presente trabalho foi apropriada, pois contemplou cada uma destas etapas de maneira a promover a aprendizagem do aluno. 
Figura 2 - O Modelo PIC

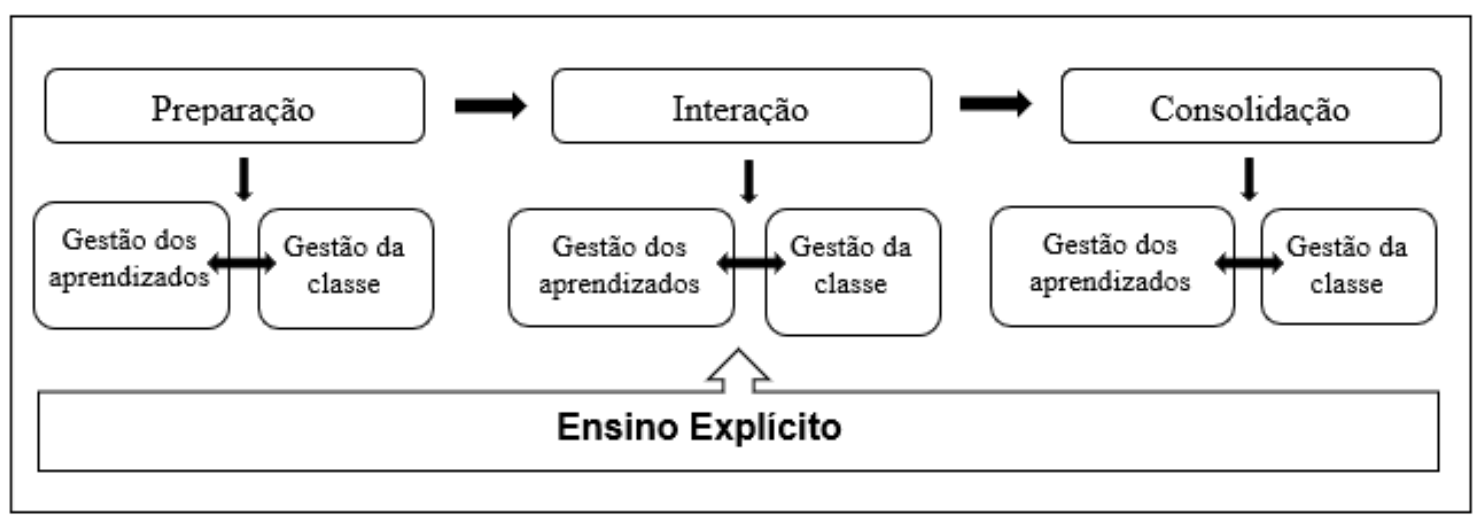

Fonte: Gauthier, Bissonnette e Richard, 2014, p. 64.

A situação de ensino descrita promoveu elementos que são relevantes ao desenvolvimento global do aluno, como: oralidade, trabalho em equipe, organização, pesquisa, apresentação das ideias e respeito aos prazos de cada etapa. Ela encerrou com uma avaliação que busca um feedback do aluno e da sua experiência frente a todo o processo.

Destaca-se que o projeto procurou contemplar desde a sua criação, aplicação e finalização, os objetivos de ampliar o conhecimento, propiciar a autonomia e estruturar as memórias dos alunos alvos da ação. Houve ainda um estímulo aos discentes do ensino fundamental, acerca das possibilidades do estudo da disciplina de Física, assim como para a sua base, oriunda da disciplina de Ciências, objeto de estudos destes alunos. Envolveu-se, nesta atividade, a escola como um todo, promovendo movimentos interdisciplinares e proporcionando aos estudantes o convívio com a diversidade existente no ambiente escolar.

Dados os elementos relevantes presentes nesta situação de ensino, o compromisso do professor ao organizar e guiar o projeto e os pontos onde a atividade poderia ser implementada, conclui-se que atividade Show da Física foi uma prática adequada, relevante, bem sucedida e que tem potencial para atingir ainda mais assertivamente o seu objetivo pedagógico.

\section{Referências}

BISSONNETTE, Steve; RICHARD, Mario. O cognitivismo e suas implicações pedagógicas. In: GAUTHIER, Clermont; TARDIF, Maurice. A Pedagogia: teorias e práticas da Antiguidade aos nossos dias. Petrópolis: Vozes, 2013, p. 393-421. 


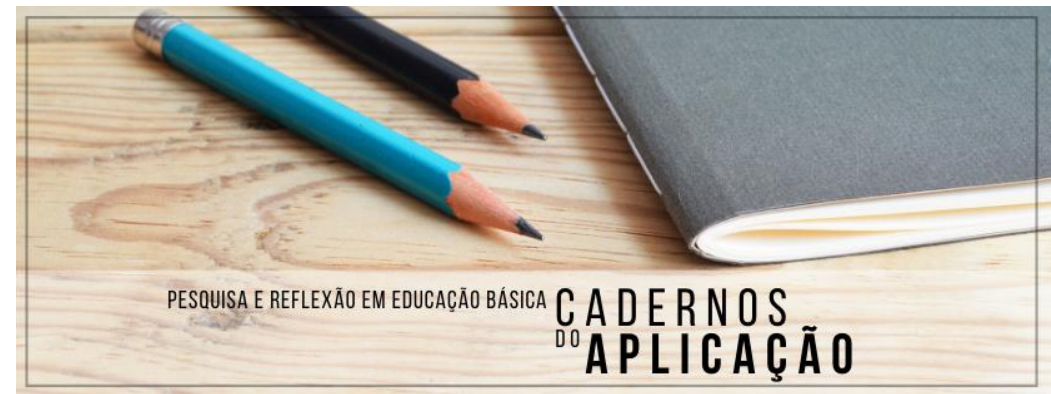

Cadernos do Aplicação

https://seer.ufrgs.br/CadernosdoAplicacao

Publicação Ahead of Print

ISSN 2595-4377 (online)

Porto Alegre | jul-dez. 2021 | v.34 | n.2

GAUTHIER, Clermont; BISSONNETTE, Steve; RICHARD, Mario. Ensino explícito e desempenho dos alunos: a gestão dos aprendizados. Petrópolis: Vozes, 2014. 335 p.

MITRE, Sandra Minardi. et al. Metodologias ativas de ensino-aprendizagem na formação profissional em saúde: debates atuais. Ciênc. saúde coletiva, Rio de Janeiro, v. 13, supl. 2, p. 2133-2144, Dec. 2008.

ROLDÃO, Maria do Céu. Estratégias de ensino: o saber e o agir do professor. Vila Nova de Gaia, Portugal: Fundação Manuel Leão, 2009. Cap. IV.

SÃO PAULO. Secretaria de Educação do Estado. Proposta Curricular do Estado de São Paulo, Física - Ensino Médio. 2009. Disponível em: http://www.rededosaber.sp.gov.br/portais/Portals/18/arquivos/Prop_FIS_COMP_red_md_20_ 03.pdf. Acesso em: 29 out. 2019.

Data de submissão: 19/11/2020

Data de aceite: $23 / 01 / 2021$

DOI: https://doi.org/10.22456/2595-4377.109304 